\section{Canada bans bisphenol A in baby products}

The Canadian government announced on 17 October that it will prohibit the importation or sale of bisphenol $A$ in bottles and food packaging for infants and newborns. The chemical is commonly used in polycarbonate plastic drinking bottles.

Animal studies have shown that bisphenol A can disrupt hormone signalling, and last month a study linked the chemical to cardiovascular disease and diabetes in humans (I. A. Lang et al. J. Am. Med. Assoc. 300, 1303-1310; 2008).

Canada is the first country to take regulatory action, according to its health minister Tony Clement.

Adults "need not be concerned" about the chemical, according to a government press release. Nevertheless, the country plans to

\title{
A sticky situation hits the record books
}

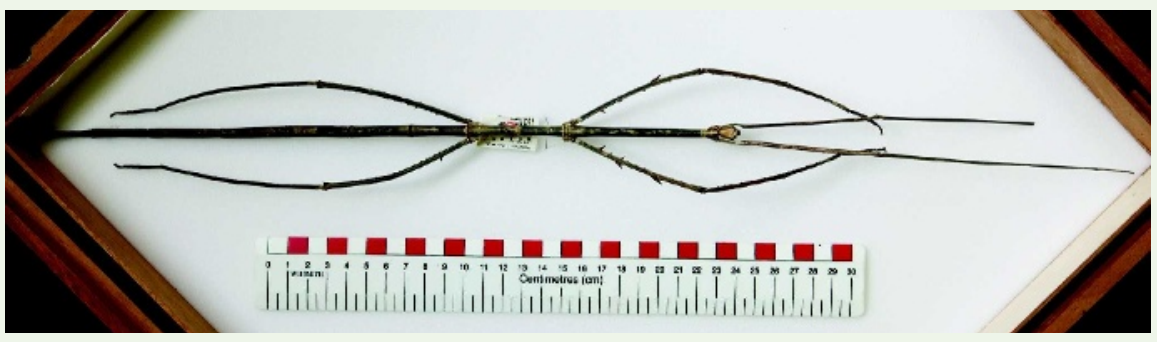

This spindly creature is the new holder of the title 'world's longest insect'. The Chan's megastick (Phobaeticus chani) was officially described in a paper last week and has a body that is 35.7 centimetres long. With limbs included, the Malaysian native stretches to 56.7 centimetres (F. H. Hennemann and O. V. Conle Zootaxa 1906, 1-316; 2008).

Phobaeticus chani breaks the record for overall length by 1 centimetre and that for body length by 2.9 centimetres. Both previous record holders were discovered more than a century ago, according to George Beccaloni, an entomologist at the Natural History Museum in London. "It is extraordinary that an even bigger species has only just been discovered," he says.

spend Can\$1.7 million (US\$1.4 million) over the next three years for further studies of adverse health effects. The ban should come into effect in 2009.

\section{US slashes acceptable limit for airborne lead}

The US Environmental Protection Agency (EPA) has revised the airborne lead standard for the first time in $\mathbf{3 0}$ years, reducing the maximum permissible concentration by $90 \%$.

The new standard of 0.15 micrograms per cubic metre is within the range recommended by a science advisory panel that evaluates air quality issues. By comparison the UK standard is $\mathbf{0 . 2 5}$ micrograms per cubic metre.

Environmentalists have generally praised the decision, although some say that the EPA missed a chance to curb emissions even more. A separate panel, focused on children's health, had recommended levels 7.5 times lower than the new standard; exposure to lead has been linked to negative effects on IQ and learning in children.

Lead emissions have dropped by $97 \%$ since 1980 in the United States, owing largely to the elimination of leaded petrol, according to the EPA. 